Accepted manuscript of article published in Mobilization: An International Quarterly by the Sociology Department, San Diego State University, 2014-12-31 (online), and available online: http://mobilizationjournal.org.

To cite or quote please refer to the published article: W. Lance Bennett \& Alexandra Segerberg (2014): Three Patterns of Power in Technology-Enabled Contention, Mobilization: An International Quarterly 19(4): 421-439. 


\title{
THREE PATTERNS OF POWER IN TECHNOLOGY-ENABLED CONTENTION ${ }^{1}$
}

\author{
W. Lance Bennett and Alexandra Segerberg
}

\begin{abstract}
Technology-enabled networks of contention differ from physically co-present networks in that communication more saliently structures relations among actors. Technology platforms may even take on some roles of organizations in providing information, distributing resources, and coordinating action. Although many observers claim that online networks tend to concentrate public displays of attention and recognition in power-law hierarchies, we propose that technology-enabled contentious networks may seek or avoid concentrated hierarchies as reflections of the participants' underlying values and technology preferences. The article identifies three ideal type power signatures in technology-enabled networks-highly concentrated, moderately concentrated, and dispersed. Different power signatures can result in similar political outcomes, suggesting that none of them represents a generally more effective way to organize power in networks. However, in particular situations, different power configurations can affect how action is framed, how individuals become engaged, and the degree of fit between mobilizations and political contexts.
\end{abstract}

Analyzing the organization of power in contentious action is a troublesome project. It is problematic to overlook it (Freeman 1975; Polletta 2013), but there is little agreement on how to define it or where to locate it in the different levels of political organization: in individuals, within groups and organizations, or within networks (Hardy and Clegg 2006; Hearn 2012; Lukes 2005). This article concentrates on one specific aspect of power that affects the success or failure of many technology-enabled mobilizations: the constructive capacity to shape common attention and action. In particular, we explore whether different structures of recognition and attention surrounding leadership directives, framing cues, and other contributions to the mobilization process affect how issues are framed, action is coordinated, and how successfully various outcomes are attained.

If the organization of power in contention is a complex process, its relationship to political outcomes is particularly difficult to pin down (Amenta, Caren, Chiarello, and $\mathrm{Su}$ 2012; della Porta and Diani 2006; Giugni 1998; Tarrow 2011). The growing importance of

\footnotetext{
${ }^{1}$ The authors gratefully acknowledge the research funding provided by Swedish Research Council grant Nr. 421-2010-2303, the research assistance of Michael Barthel, and the constructive input offered by Nina Eggert, Elena Pavan, and the article reviewers.
} 
communication technologies in networked protest complicates the analysis even further. Tracing diverse structural configurations in physically co-present civil society networks, Diani (forthcoming) observes that different configurations may produce similar outcomes, but leaves open the question of whether networks that are significantly organized with communication technologies may display similar variation. It is possible that technologyenabled networks simply mirror established views of power that highlight relationships among actors and the role of organizational mechanisms (material and nonmaterial resources, frames, leadership) that create scale and coherence in contentious action (Tarrow 2011; McAdam, Tarrow, and Tilly 2001). At the same time, communication technologies present new ways of configuring relational patterns of the kind examined by Diani and McAdam (2003), particularly by enabling more flexible ties among individual and organizational actors.

In determining how technology may affect mobilization, two aspects of communication in networks require more consideration. First, communication technology operates differently in structuring networks depending on whether it merely amplifies and economizes communication processes that are already occurring, or whether technologies act as organizational agents and processes. Second, it is important to reconcile these different roles of communication with the many studies indicating that large online networks tend to drift towards a so-called "power-law" configuration, a hierarchical structure in which a few actors dominate the attention and receive disproportionate recognition from others. We resolve this conceptual tension regarding the role of communication technology by showing that activist values and organizational preferences can alter the structures of communication networks. Moreover, we also show that communication systems in particular mobilizations may shift over time and circumstance between hierarchies directed by a few groups or individuals and broader conversations in the crowd that also have the potential to shift agendas, introduce new ideas, and shape action. In other words, power may be fluid even within the same movement or protest.

There are many ways to conceptualize power, which is often discussed in terms of the distribution or concentration of resources used to shape the actions of others. We propose that the overarching structure of publicly displayed attention and recognition in networks offers a measure that bridges several of the more local sites of power (including interpersonal and interorganizational) in complex technology-enabled networks. Public displays of attention and recognition in such networks can, for example, involve hyperlinking or retweeting, which establishes structures of attention and recognition in networks. Attention and recognition in various forms have long been examined in relation to organization (e.g., Weber 1978), and 
these concepts are now assumed to take on special significance in the media ecologies associated with many instances of contemporary contention. Our analysis addresses two types of questions. The first concerns network structure and the organization of power more directly: Must networked contention always tend towards hierarchical distributions of public recognition and attention? And how do particular distributions of attention and recognition affect popular input in shaping and framing action? The other front in our analysis shifts focus beyond the organization of attention and recognition in technology-enabled networks to political outcomes: Are the relationships between network power structures and political outcomes in technology-enabled contention as fluid as noted in earlier social movement and civil society studies?

The next two sections of this article lay out the puzzle of "power-law" attention and recognition hierarchies in technology-enabled networks of contention. It is crucial to understand the findings about power laws in online networks in order to develop a framework that accommodates both intentional and unintentional variations on hierarchy. In the following part of the article, we argue that activist values and preferences can and often do underpin the communication flows in a network, and we identify three different ideal-type patterns or "power signatures" for distributing attention and recognition of various sources of information, ideas, and frames. Next, we introduce case studies to sketch the internal dynamics of each type of communication power signature and suggest that, similar to the physically co-present networks studied by Diani, none of these produces clearly superior political outcomes. The conclusion addresses the question of how different power signatures may interact and reflect underlying struggles among activists regarding preferred ways of organizing communication and attention processes, and identifies three areas for future research.

\section{ORGANIZATION IN TECHNOLOGY-ENABLED NETWORKS}

A key distinguishing feature of technology-enabled networks of contention is the salience of the organizational dimension of communication (Bennett and Segerberg 2013). This means that discursive, symbolic, and technological communication mechanisms can play prominent roles in structuring relations among actors through processes of providing information, distributing resources, and coordinating action. This is one aspect in which large-scale technology-enabled networks may differ from conventional social networks. It is also this organizational capacity of digital communication technologies that makes understanding the 
origins and pervasiveness of power laws of attention and recognition in communication networks particularly pressing.

The organizational role of communication can be understood when contrasted with more familiar communication processes, such as sending and receiving messages. Most organizations and many activists today use digital media to send and receive messages about themselves and their causes. While digital media may reduce the costs of communication, and reach audiences more easily than through conventional mass media strategies, such digitally enhanced communication typically does not fundamentally change an organization, its relations with members, or its co-location with others in a network. Such messaging networks might be described as technologically enhanced (see also Earl and Kimport 2011). By contrast, there are instances in which technologies do more than facilitate the sending and receiving of messages; they may also enable various kinds of organization itself, taking over some or even all of the roles of conventional brick and mortar organizations in the process. We have previously observed two ideal type ways in which communication enables organizational processes in networks characterized by what we term "connective action" (Bennett and Segerberg 2012, 2013).

One form that we call "organizationally enabled" connective action is characterized by traditional NGOs and SMOs entering into loose networks around flexible, inclusive, and easily personalized framing of common issues. The resulting networks typically share technology with resource-poor organizations, while inviting individuals to personalize common issues and share them in turn with their own social networks. An example is the "put people first" protests organized in 2009 by NGO networks in London following the global financial crisis. Large NGOs such as Oxfam stepped back from branding the protests around their organizational identity and instead enabled the growth of organizational and individuallevel networks through stand-alone campaign sites that invited individuals to send their messages directly to the G20 and to attend demonstrations in London and around the UK.

A second form of connective action, which we term "crowd-enabled," involves a few organizations in prominent roles, with many technology platforms (e.g., organizational websites) dynamically linked through switching and stitching technologies (e.g., Twitter, SMS networks, and other highly individualized technologies). This network type was evident in the Tahrir Square uprisings in Egypt in 2011, the 15 M movement of the Spanish Indignados, and the Occupy Wall Street protests in the same year, all of which developed sustained organization while keeping formal organizations and leadership in the background. For example, in their study of the $15 \mathrm{M}$ protests, Anduiza, Cristancho, and Sabucedo (2014) 
found that the crowd-enabled action differed from conventional social movement mobilizations (a general strike, demonstrations in favor of regional autonomy, and antiabortion protests) in that fewer of the organizational affiliations identified by the Indignados had street addresses (meaning they existed only online), those organizations were substantially younger, and they disproportionately did not permit actual membership.

Both types of connective networks involve technologies in organizational roles that may substantially change the relationships among and between organizations, individuals, and technology platforms in the generation and coordination of protest actions and frames. But the question is whether the organizational role of technology necessarily skews the distributions of attention and recognition, and the power relationships that are assumed to be entailed. In particular, does technology-enabled contention necessarily conform to any particular pattern of dominance by some actors (including by technology platforms) over other agents in the network?

\section{THE POWER LAW AND TECHNOLOGY-ENABLED NETWORKS}

Understanding technology-enabled contention is complicated by the intriguing observation of a "natural" tendency of large online networks to form attention or recognition hierarchies that give power (to set agendas, frame issues, and promote actions) to the dominant actors at the top. The pattern is frequently observed in some technology spheres, but its significance in contentious networks is not fully understood.

In a typical power-law network, each node is ranked by its recognition or inlink value (N) so that each node after the first ranking receives no more than $1 / \mathrm{N}$ the degree of recognition received by the top node. Thus, the second-ranked node receives no more than half the links given to the top node, the tenth ranked node receives no more than one-tenth, and so on (Shirky 2003). Such distributions are described as scale-free, meaning that even as the network grows, the steepness of the hierarchy remains the same (Barabási and Albert 1999). Network theorists have demonstrated this pattern in large networks that emerge spontaneously through various ecological processes as different as tributaries in river systems, wealth distributions in societies, and linking among websites across the Internet (Barabási and Albert 1999; Barabási 2003). There is also rich evidence from online collaboration communities such as Wikipedia and open source software networks that a few producers dominate while the vast majority of members do relatively little (Wilkinson 2009), resulting in an oligarchic drift (Shaw and Hill 2014). The significance of a few highly motivated actors 
has been similarly highlighted in political mobilizations (Chadwick 2013; Earl and Kimport 2011; González- Bailón, Borge-Holthoefer, and Moreno 2013; Karpf 2012; Margetts, Hale, and Reissfelder 2013), and power-law distributions are regularly identified in contentious communication, from the online circulation of environmental advocacy clips (Baym and Shaw 2011) to Twitter streams during the 2011 Egyptian protests (Meraz and Papacharissi 2013).

Much of the debate about power laws in political communication has revolved around the blogosphere as the paradigmatic case, and around the power that specifically follows from the concentration of recognition and attention. In a central contribution, Shirky (2003) argued that power laws apply naturally to communication networks, such as the linkages among blogs that produce a few dominant ones — often elites — while the vast majority that make up the long tail are largely ignored (see also Farrell and Drezner 2008). Hindman (2008) extends a similar argument to cover most conventional political and election sites, which form network hierarchies that are dominated by a few sites, while the rest get little recognition and have little influence.

In these cases, the pattern of recognition and attention emerges as the network grows and as new actors tend to focus on and link to those that are already most visible, popular, and respected in a process of preferential attachment (Barabási 2003). In a context where information is abundant, the capacity to attract attention becomes potent. The actors at the head of recognition and attention distributions have the power to include and exclude issues, frames, and contributors as they filter and curate material from other parts of the network in their own output. O'Neil $(2009,2014)$ conceptualizes this capacity to concentrate practical and symbolic resources in the form of hyperlinks as a form of "index authority," recognizing that highly in-linked sites tend to rank highly in search engine indexing. Meanwhile, the concentration of focus has also been associated with the capacity of the entire blog network to reach a broader public, in particular via the mass media, such that "the extent to which the distribution of links is skewed will have key consequences for how the blogosphere affects politics" (Farrell and Drezner 2008: 18).

There are two problems with extending these conclusions to technology-enabled networks of contention, both of which have to do with how such networks are contextualized (shaped to fit political contexts) by the actors in them and by the analytical choices of observers. ${ }^{1}$ A first conceptual problem involves the difference between naturally emergent online networks and those shaped to some degree by the intentions and designs of the actors. For example, Shirky (2003) stressed that power laws are natural (and socially neutral) in 
communication networks, and many of the key examples emerge from straightforward ecologies of popularity (e.g., blog links and traffic flows). By contrast, contentious action often involves intentional design choices made by participants to resist hierarchy and to share recognition. This stance is common among social movement organizations that seek to maximize inclusion and the spread of recognition (Ackland and O'Neil 2011; Diani forthcoming). It may also be found in less organization-centered protests, in which activist commitment to inclusiveness and diversity shapes the forms of physical assembly and guides the uses of networking technologies to link dispersed gatherings and actively engage spectators (della Porta 2013; Kavada 2013). The mere intention to avoid hierarchy and promote inclusion does not dispel authority or inequality (Polletta 2013; Postill 2013; O’Neil 2009), but the hierarchical distribution of recognition within these contexts may, nevertheless, be blunted.

A second, more analytical, complication is that different ways of slicing the same networks and data may yield more or less concentrated distributions. For example, a careful study of environmental activist networks by Ackland and O'Neil (2011) showed that the "frame network" of content shared by the organizations on their websites displayed a centralized distribution, while the (intentional) hyperlink network between the sites was more dispersed, in keeping with the organizations' commitment to share recognition equitably. Such contextualized mapping of networks suggests the need for nuanced analyses of network dynamics across different dimensions of the network, as well as over time and in response to particular conditions.

These problems with generalizing claims suggest two broad questions about the organization of power in technology-enabled contention. First, do power laws necessarily characterize technology-enabled networks? What do particular distributions of attention and recognition in the network mean for the capacity to facilitate popular input in the shaping of the action and its various dimensions, such as issue framing? Second, turning to the importance of such distributions, are differently patterned networks more or less effective in establishing issue frames in the broader public discourse or in achieving material goals? We explore these questions through case studies that illustrate three possible ideal type distributions of publicly displayed attention and recognition in technology-enabled networks. 


\section{THREE PATTERNS OF POWER IN TECHNOLOGY-ENABLED NETWORKS}

Distributions with a high concentration of attention and recognition may be only one pattern found in large-scale technology-enabled contention. Our own work suggests that participants often have greater agency in shaping the organization of power than is usually acknowledged in the power-law discussion. In fact, we have identified three analytically distinct patterns"power signatures"-for the distribution of publicly displayed relational recognition in networks: highly concentrated, moderately concentrated, and broadly distributed:

- At one end of the network power spectrum, recognition and attention are concentrated and hierarchical, creating a steep power curve with a few actors commanding recognition and attention (receiving links) from a large percentage of others in the network. This configuration corresponds to the classic power law of networks in which many actors link to a few top actors, while the rest receive relatively few links from each other. Information and action tend to flow top down in these networks.

- The mid-range of network power structures is characterized by moderate power signatures in which a greater number of organizations or individual actors are accorded recognition and attention by others in the network. This structure results in a gently sloping power curve with a more gradual tailing off, and reflects greater shared recognition amongst actors. Collaborative decision making and information framing characterize these networks.

- At the other end of the power spectrum are more horizontally distributed "networks of networks" that may be difficult to render as single networks due to fragmentation, sporadic connections, and changing intersections over time. These dispersed clusters of associated actors may link episodically when coordinating action or information, and then dissolve back into differently networked fragments addressing local or topical concerns. Information and action plans in these networks can emerge from multiple locations and circulate through many filtering and gatekeeping processes of the crowd.

\section{Case Selection}

Our goal was to select cases that illustrate these three ideal types of power in networks, and that offer some broad comparisons among political outcomes. Selecting perfectly comparable cases is tricky. Two cases draw from our own previous research on economic justice mobilizations. The case illustrating a moderate power curve is the 2011 Robin Hood tax campaign in the UK, which was sponsored by a large, loosely-tied coalition of NGOs and 
SMOs that created a common organizational platform (robinhoodtax.org) to help individuals understand the problem of speculative financial transactions and take action in supporting a tax that would limit unproductive investment and would redistribute some of the profits when such speculation occurred. The case illustrating a broadly distributed network-of-networks pattern is the 2011 Occupy Wall Street mobilization in the U.S., which contained so many active sub-networks, and technology platforms linking them, that an encompassing network structure was defeated by the many disjointed networks that intersected episodically around events, campaigns, and pulsing resource flows from the large crowd of core activists, virtual supporters, and distant spectators (Bennett, Segerberg and Walker 2014).

We did not have a clear case of a power-law hierarchy from our own previous research. However, we became intrigued by a study by Benkler et al. (2013) of online discussions about proposed internet piracy and intellectual property legislation in the U.S. Congress that occurred in roughly the same time period as the other cases. Their cumulative network data over a time span of more than a year showed that the volume of interlinked content in the networked sphere grew steeply around the week of major online protests, with a few sites appearing to dominate the online discussions. Nevertheless, the week-by-week analyses showed great variation in the mix of sites, content, and structure. Our own analyses of the raw inlink data from this study corroborates these findings, and reveal that the only period in which the network approached a power-law structure was during the week of major protests in which key sites, such as Wikipedia and Google, directed millions of individuals to send messages to Congress. We chose this case in part because the sudden shift from moderate to hierarchical linking patterns reinforced our suspicions that the organization of power in largescale technology-enabled networks may shape-shift over time and in response to different contexts and contingencies.

These cases are intended to illustrate different configurations in the organization of power that may occur in technology-enabled networks. Far from being definitive, they are intended to open up further research.

\section{Conceptualizing Political Outcomes}

The political outcomes we associate with each case are also intended to be illustrative and to suggest further research. As noted, tracing the outcomes of contentious politics is complex. We sketch public outcomes in basic terms in two broad areas. First, there are public discourse or framing outcomes. This area describes the broad public resonance of framing on three topics: the frame of freedom and censorship, which arose from internet piracy legislation; the 
framing of speculative financial transactions as a social problem (and the "Robin Hood tax" as a solution); and the inclusive frame of "We are the 99\%," which accommodated different actors and ideas in the Occupy crowd and led to more general discussions of economic inequality in society. A second type of outcome involves material political gains that may be sought and won through targeted actions such as the defeat of the proposed internet piracy legislation in Congress, the passage of financial transaction taxes in a number of EU nations, and the development of policy proposals for increasing taxes on the rich and raising the minimum wage for the poor in the U.S.

\section{THREE PATTERNS OF NETWORKED POWER}

From a theoretical standpoint, these cases show how different network power signatures, constituted by distinct distributions in public displays of attention and recognition, reflect three patterns: first, the interactions among the organizational preferences of actors; second, the opportunity structures in political situations; and, third, the communication repertoires and technologies that mediate organizational preferences and political opportunities. The cases all suggest that differently organized network power distributions can achieve similar outcomes.

\section{Concentrated Network Power: Protests against Internet Piracy Legislation in the U.S.}

The protests against Internet piracy legislation began as dispersed and shifting online stories and discussions about the meaning of pending legislation in the U.S. Congress. The protests then shifted dramatically into a highly concentrated network during the week of major online protests demanding that Congress not pass the legislation.

The proposed law began as the Combating Online Infringement and Counterfeits Act and took different forms in the two legislative chambers of Congress: as the Stop Online Piracy Act (SOPA) in the House and the Protect IP Act (PIPA) in the Senate. Public engagement with this pending legislation began in 2010 with concerns that Internet service providers and other online entities such as Wikipedia and Google would be forced to police users for using content possibly owned by others. Relatively sparse discussions on blogs, zines, and tech media such as Wired and CNET expanded over time to gaming sites, advocacy organizations such as the Electronic Frontier Foundation, and user communities such as Reddit. The shifting discussion networks surged more than a year later when Congress was ready to vote on the legislation, and organizations with large user communities such as Reddit, Wikipedia, and Google directed online protests at Congress during the week of January 16, 2012 (Sell 2013). A variety of protest actions and frames were discussed in the 
diverse online communities prior to the vote, including the targeting of specific congressmen or highlighting the impact on innovation and economic entrepreneurship. By the day of the protest, the dominant frames centered on the need to stop censorship and protect freedoms of various kinds (e.g., free speech, freedom of the internet) (Langford 2013; Loudon 2014).

Benkler et al. (2013) tracked the flow of links to web content about the issue over this extended period, tracing the development from the dispersed community discussions to the common day of protest. We focus on the inlink data as a basic measure of online attention and recognition. The formal method for determining whether a concentrated power law or a more moderate power signature is operating in a network is to take the log of the distribution of links or ties received by each node in the network from the others. If the log line has a relatively steep slope (e.g., greater than -1 , and typically between -2 and -3 ), and the distribution of nodes in the tail fits the line fairly well, then a power law is most likely operating. ${ }^{2}$ The graph in figure 1 shows what this type of network looks like.

Figure 1. Typical Shape of a Power-law Distribution of Inlinks over Nodes in a Network

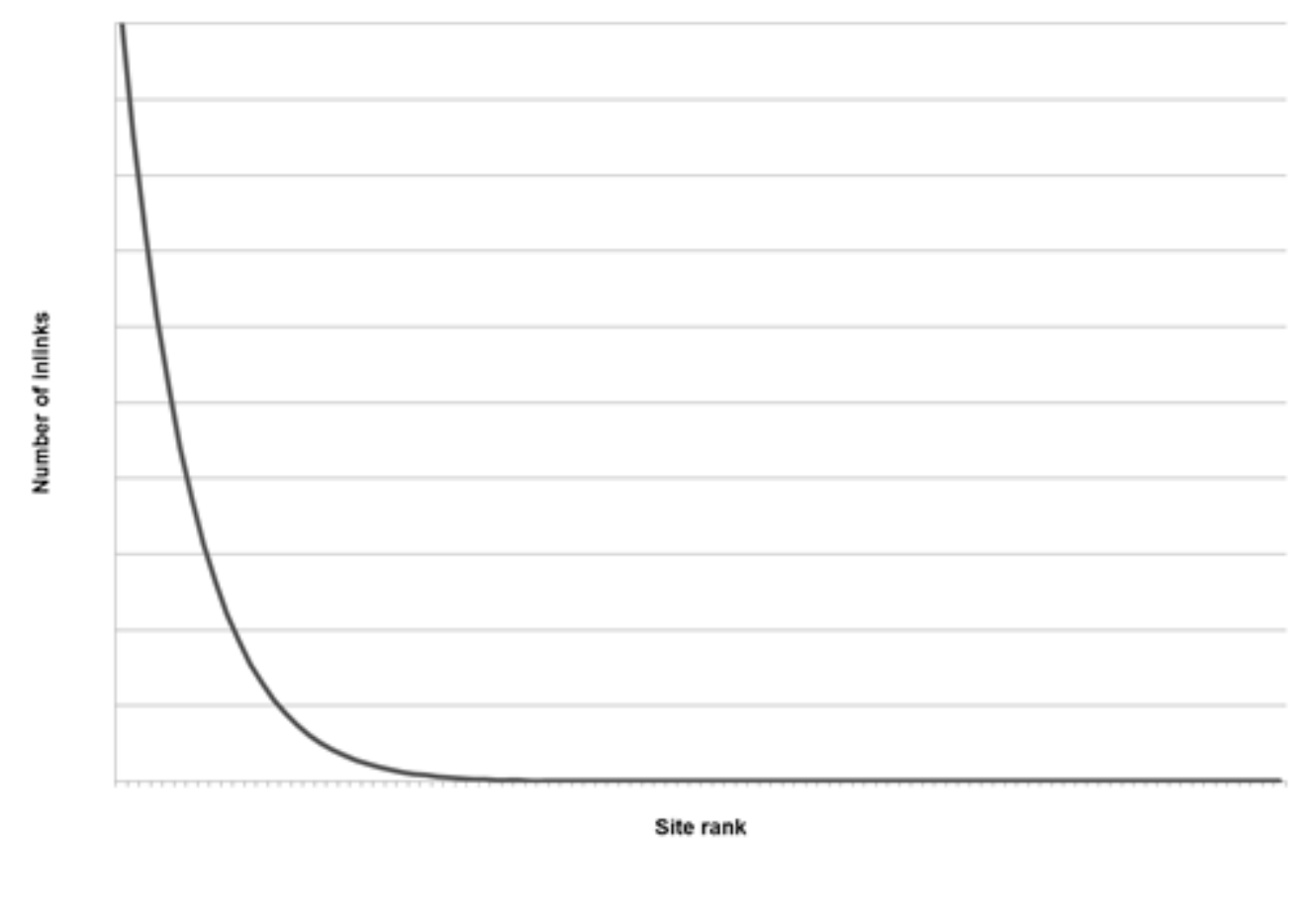

The excellent over-time visualizations by Benkler et al. (2013) show that different sites drew attention in different weeks as new topics developed and became more clearly framed. ${ }^{3}$ However, both the volume of content and the hierarchical pattern of linking grew dramatically into a steep power curve on the eve of the vote in Congress. On the day before 
the vote, large Internet sites such as Wikipedia went black and thousands of smaller sites linked to them in order to encourage users to urge Congress not to pass the legislation.

Figure 2. Power-law Curve of SOPA/PIPA Online Protest Network January 16-22, 2012

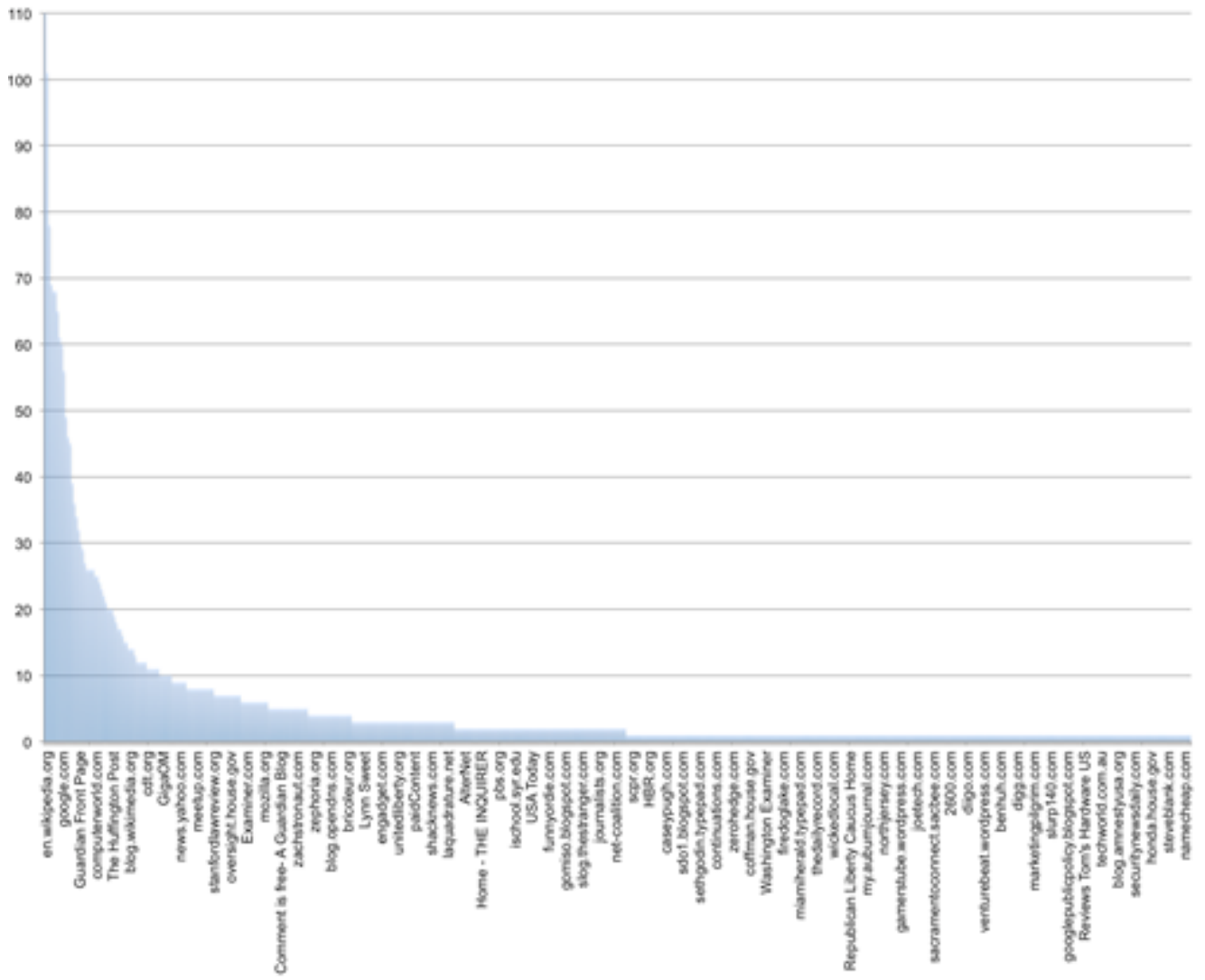

Our analysis of the inlink data shows that both the number of sites in the network and the inlinking volume jumped dramatically during the main week of protests. Fully 862 sites with 2862 inlinks were mapped the week of January 16, 2012, compared with 342 and 727 the previous week, and just 47 and 30 the first week the network was detected in October 2010. The shape of the inlink distribution during the online protest week is shown in figure 2. A reliable power-law slope calculation would require a much larger network tail than this one naturally contained. However, a rough indication of the contrast between this protest network and earlier weeks in the life of the issue sphere can be seen by calculating the percentage of top sites that account for at least 50 percent of all the inlinks in the network. In the early weeks of 2010, when the networks served primarily as discussion spheres and outcomes were best understood as issue framing, the total inlinks were distributed over 25 to 28 percent of the top sites, making those networks roughly comparable to the moderate power distributions discussed in the next section and shown in figure 3 below. By contrast, during the culminating protest week the distribution shown in figure 2 concentrated 50 percent of the inlinks in just 6 
percent of the top sites. Benkler and colleagues (2013: 44) note the emergence of a steep public "attention backbone" and argue that, far from diminishing the impact of smaller sites and their individual user communities, it magnified individual contributions by transferring input up the network to sites receiving greater attention.

The short-term material outcome in this case is clear. The deluge of public concern was noteworthy for its volume, concentration of impact, and commonality of messages, and it resulted in the legislation being stopped - at least in its then-current form. The majority of the demands to stop the legislation passed through the top sites in the network that offered tools for targeting and transmitting individual concerns. Various reports showed that between ten and fourteen million individual protest messages were received in a single day (Greenberg 2012; Weisman 2012). Social media companies such as Twitter reported millions of communications channelling personal social networks into the protests (Twitter 2012). In terms of public discourse, the protests focused public attention on what for many seemed to be an abstract issue, and framed it compellingly in terms of freedom and censorship. The discourses and policy goals stemming from this mobilization have continued to shape political discussion and claims for years after these protests ended.

The week of targeted protests illustrates the growing importance and effectiveness of online mobilizations of the sort described by Earl and Kimport (2011). They also show how crowd organization can shift the intentionality of activities (from issue discussion to targeted protest action) and, in the process, can shift network relationship structures (from moderately distributed recognition and attention to a concentrated pattern). 
Figure 3. Four Empirically Observed Networks with Moderate Power Signatures

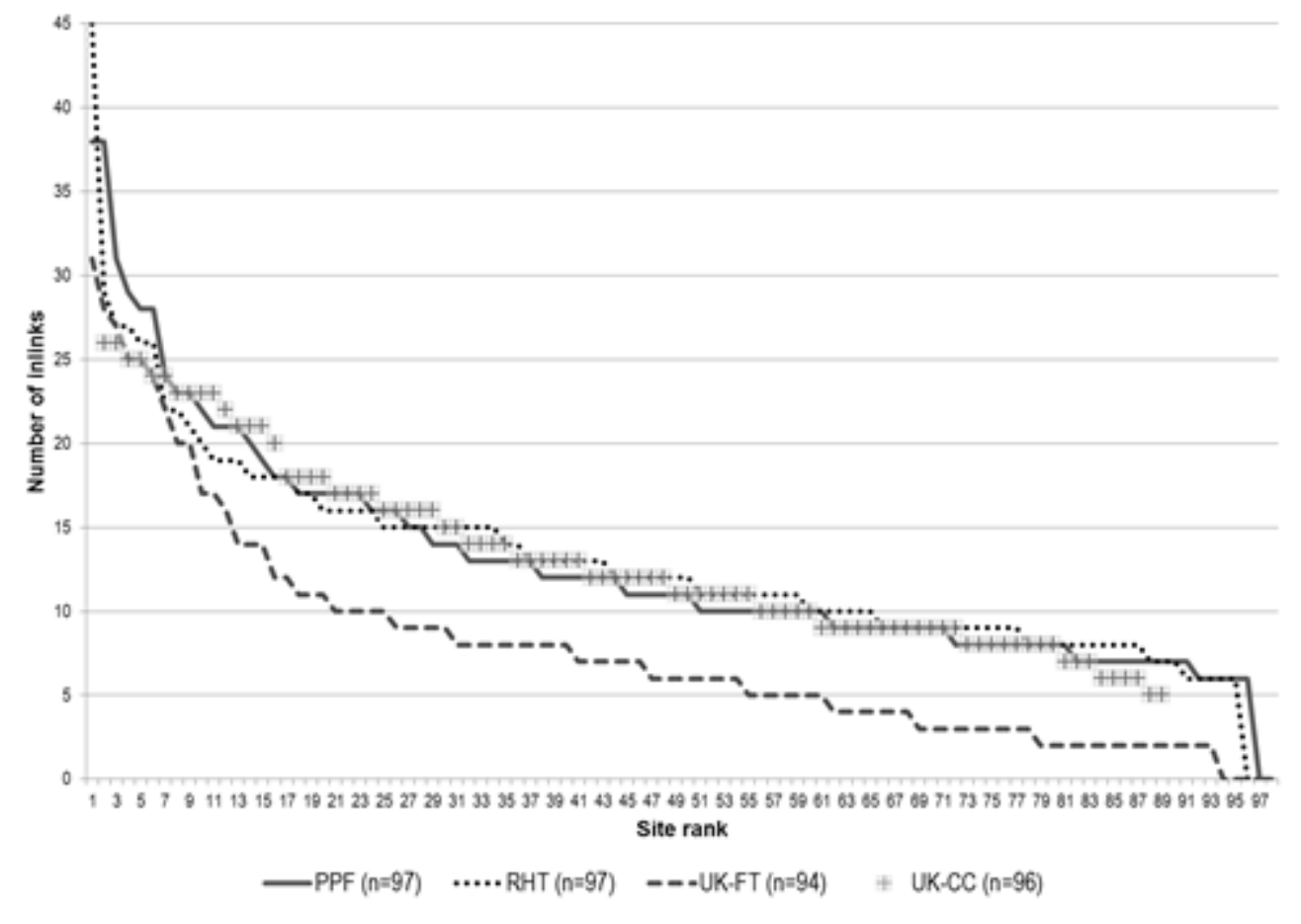

Note: The networks are: Put people first protest, the UK fair trade and climate change networks, the Robin Hood tax campaign; Source: Adapted from Bennett and Segerberg 2013.

\section{Moderate Network Power Signature: The Robin Hood Tax Campaign in the UK}

Although it can be tempting to see power laws wherever one looks in political networks, other distinctive configurations reflect different organizational values and political conditions. As noted, an alternative pattern of networked power occurs when actors make intentional design choices to form loosely tied coalitions that share public displays of recognition and attention more broadly.

Cases of this can be found in issue advocacy areas, such as economic justice and climate change politics, where coalitions may involve hundreds and even thousands of organizations joining around simple messages and campaigns. The simplicity of such network frames as "Put people first," "Stop climate chaos," or "Robin Hood tax" often reflect intensive efforts to create networks that, in the words of one NGO executive, "cut the diamond" of network inclusion to refract the greatest light, or invite the greatest possible inclusion of organizations and individuals (Yanacopulos 2009: 73). This design process typically results in networks with moderate power signatures, such as the four shown in figure 3. Three of these networks addressed economic justice issues (fair trade, put people first, and Robin Hood tax) and the fourth (stop climate chaos) organized UK protests ahead of the 2009 Copenhagen UN climate summit. We mapped the co-link organization networks on the basis 
of inlinks (representing attention and recognition) using Issue Crawler (Rogers 2004, 2013). The Issue Crawler (issuecrawler.net) in the use scenario we employed begins with a set of seed URLs from actors that we judge to be important in an issue sphere. When links from any of the seed organizations (e.g., the sponsoring NGOs of the Robin Hood tax campaign) go to other starting points or new organizations that link to actors included in the emerging network, they are drawn into the network. The network structural map is organized in terms of the numbers of links sent and received by the various organizations in the co-linked network. The four networks in figure 3 were mapped in roughly the same time period in 2009-10 in the UK. They all display moderate power curves: in each case large numbers of organizations share recognition (receive inlinks) from other actors in the network (50 percent of the total inlinks are distributed between 23 to 35 percent of top sites). Our illustrative case is the Robin Hood tax campaign, which displayed the highest level of shared recognition, with 50 percent of the nodes in the network linking to the top 35 percent of sites.

The UK Robin Hood tax campaign represents an organizationally enabled connective action network with a moderate power signature. The key policy goals were to impose taxes on financial transactions to reduce speculative volatility in the finance sector, and to use the generated funds in redistributive efforts to fight poverty and climate change. This campaign had roots in the Tobin Tax Network led by the NGO War on Want, and drew on framing processes stretching back to at least the 1990s. The early framing of the policy goal as the "Tobin tax" referred to the Nobel economist who promoted a financial transaction tax as an economic stabilization policy. However, this did not capture the popular imagination, and Tobin refused association with economic justice activists. War on Want then published a proposal for a "Robin Hood tax" in 2001, evoking the idea of taking from the rich to give to the poor. This simple and easily personalized frame attracted a large, loosely linked network of some forty NGOs that formed the Stamp Out Poverty Coalition in 2005 and grew over the following years (Brasset 2012). The public face of the Robin Hood tax campaign, and its most visible organization, was a website launched in 2010 that offered interactive technologies to help participants "spread the word" by telling their personal "Robin Hood" stories (robinhoodtax.org). The mobilization of a broad public was aided by sophisticated uses of Twitter, YouTube, Flickr, and Facebook, and by downloadable digital resources in the form of masks, posters, badges, videos, logos, and photos. Following the launch of the 2010 campaign website, the network inlink structure exhibited the moderate power signature shown in figure 3. The same pattern persisted in repeated crawls even as the campaign coalition grew from some 60 organizations, around the time of its launch in 2010, to 118 in late 2013. 
This technology-enabled campaign attracted broad public participation, and became endorsed by a spectrum of public figures, including politicians, religious leaders, and business leaders. In 2012 and 2013 the European Commission proposed that EU members adopt the tax, but strong objections were raised by the UK, among other countries. The European Commission then allowed member nations to implement the tax voluntarily under a coordinated plan to begin in 2014. Eleven nations joined this plan, including France, Germany, and Italy. The campaign continued after this EU policy success, with continuing focus on mobilizing individual participation through sharing personal stories. By 2013, the UK campaign had more than 15,000 Twitter followers, 266,000 Facebook friends, and one million views of its YouTube Channel, which contained videos of popular actors such as Bill Nighy playing a woefully out-of-touch banker. ${ }^{4}$

While the material political outcomes of the campaign are easily documented, assessing the impact of the campaign on the public discourse and issue framing process requires a deeper analysis. We used the semantic networking tool Silobreaker (silobreaker.com) to track media debates in the UK over the course of the campaign (201113). Silobreaker searches a dynamic database (continuously updated with user source requests) of online sources for news articles, blogs, and websites, which can be filtered by language, country, and media type. We searched for patterns of word association and source attribution in UK news articles and blogs. The Silobreaker algorithm delivers patterns of prominence of key search terms in the media database, along with chains of association between those key words and other terms and sources that appear with them in articles. Thus, "Robin Hood tax" occupies the center of a large discourse space, as a term occurring frequently in 185 news articles and blog posts during the month of this crawl, and "RHT" coappeared in articles prominently mentioning taxes, the G20, the European Union, the Church of England, and other players in the political discussion of a financial transaction tax. The closer these other terms are to the Robin Hood Tax on the map, the more often they are associated together in the same articles. Thus, in this semantic network, based on 185 major news articles and 24 blog posts, we see David Cameron, then Prime Minister, appearing frequently in articles expressing concern that the tax might drive financial transactions out of the UK, while articles with other sources-such as then-Archbishop of Canterbury Rowan Williams and the G20 - tended to contain more positive endorsements of the tax. Other articles explained that James Tobin was one of the originators of the idea, which had been appropriated by the economic justice movement that included NGOs such as Oxfam (also shown in the discourse network). The semantic map in figure 4 shows the emerging political 
configuration of actors engaged in the move from a public protest movement (involving civil society actors such as trade unions, Oxfam, Occupy Wall Street, and the Church of England) into different political arenas such as the UK government, the G20, the EU, and the IMF.

Figure 4. Semantic Network of UK Robin Hood Tax Media Debate, December 2011

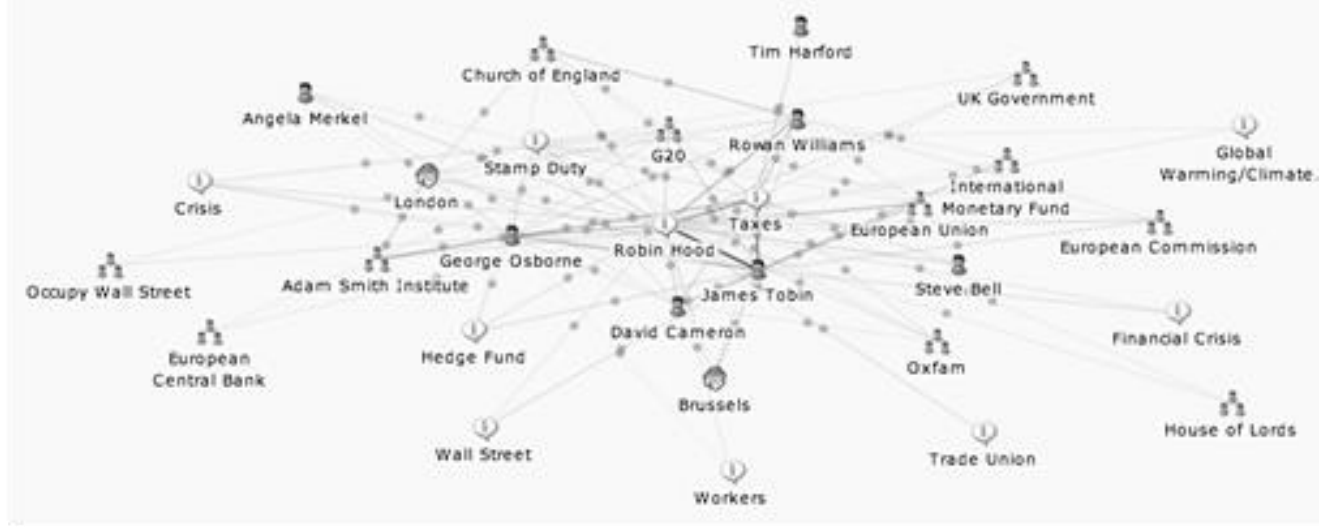

Note: Based on 185 online news articles and 24 blogs. Source: Silobreaker, with permission.

A similar analysis of media coverage during November 2013 showed that as the issue moved from the issue framing and public discussion spheres and into EU policy arenas, the main policy issue frame shifted from Robin Hood tax to "financial transaction tax." In this phase, the discourse space became dominated by policy language issued by institutional sources (European Commission, European Parliament, European Union) and government heads (e.g., David Cameron and Angela Merkel). The media debate by this time was even more prominent than before, with 233 online news stories and 61 blogs in the UK during the month of November 2013.

Perhaps the transnational scope of the Robin Hood tax campaign and the movement between discourse and policy arenas favored a stable moderate power configuration, with many organizations mobilizing both publics and their insider political networks over a long period of time. It may be that the concentrated power curve of the SOPA/PIPA protests was better for focusing more intense pressure on a single institution over a shorter period of time. Further research is needed to shed light on how technology enables networks to achieve fit with political opportunity structures and with other contextual factors. For now, we turn to the question of whether highly dispersed power networks such as Occupy Wall Street can also have a similar capacity to shape public debate and political outcomes. 


\section{Dispersed Network Power: Occupy Wall Street and the Inequality Debate in the U.S.}

In contrast to the coherently organized networks represented by concentrated or moderate power signatures, a stylized view of a dispersed power signature is shown in figure 5. Several disjointed networks are shown in the center view. The left view shows the network stack from the top. These disjointed networks may become more or less integrated by being dynamically threaded or stitched together through flexible networking technologies-shown here by the threads connecting the networks in the right hand view. Stitching can occur through, for example, word of mouth, SMS or email, or social technologies such as Twitter. Each method of stitching may achieve different results in terms of coherence and capacity for concerted action. However, the dynamics of linking disjointed networks makes it difficult to model a coherent or stable power curve. The organization of power in terms of attention and recognition may be better understood as cumulative microprocesses that gather dispersed individuals or groups in the production of various action frames (e.g., "we are the 99\%") and in the coordination of protest events. ${ }^{5}$

Figure 5. Distributed Network Power Signature Showing Network of Networks
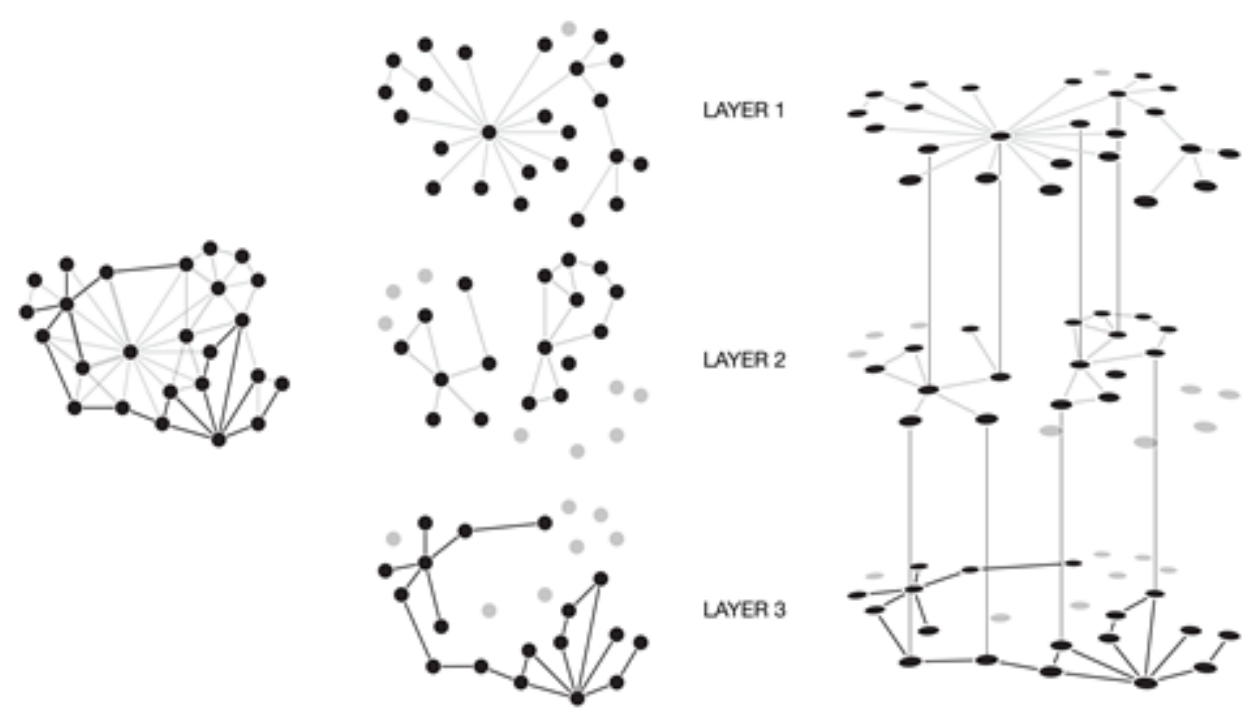

Note: Used with permission of Martin Krzywinski, University of British Columbia Cancer Research Center (hiveplot.com).

We apply this model to the "network of networks" in the Occupy Wall Street protests in the following analysis. The different networks represented in the center view of the figure (and seen from the top in the left view) might include Facebook networks, city website and campaign coordination networks, or Livestream media feeds, all of which were loosely 
integrated or stitched together by Twitter hashtags represented by the vertical threads in the right view.

The Occupy Wall Street protests involved occupations of public spaces in dozens of U.S. cities and locations around the world during the fall of 2011, and tailing off into the next year. The symbolic center was the first encampment in Zuccotti Park near Wall Street, with activists holding meetings and staging events to highlight greed and corruption in the financial sector, and to more generally frame various problems of social and economic inequality. Unlike the organizationally enabled Robin Hood campaign with its carefully honed frame, Occupy involved more loosely generated, crowd-sourced personal action frames, most notably the slogan "we are the 99\%" (Gaby \& Caren 2012).

While the physical occupations gave the movement symbolic focus (Gerbaudo 2012), the action in and around the camps intersected with networks enabled by dozens of digital media platforms that gave the larger crowd broad connectivity and dynamic capacity to shift focus and action. Our link analyses of a number of diverse networks in the Occupy crowd shows that the key stitching mechanism across the many subnetworks was Twitter, which connected people through thousands of digital streams and distributed resources and artifacts (photos, videos, text) across a variety of locations (Bennett, Segerberg, and Walker 2014).

The analyses of public discourse and material political outcomes are more intertwined in this case than the others. Despite the proliferation of themes and actions, most attention amongst the activists revolved around issues related to inequality. These discourses were elevated by the ubiquity of the easily personalized "we are the 99\%" frame, and further dramatized in performances and protest repertoires that traveled through the crowd. Discussions of inequality moved into the mainstream media and eventually engaged political elites. As our analysis indicates, prior to Occupy there was little focus on inequality in the U.S. news media, but the growth of inequality and the excesses of the rich became the most prominent subtext in media discussions about the protests, often framed by the " $99 \%$ " meme.

Occupy protesters targeted elite political actors and institutions, from marches down Wall Street to demonstrations at Obama and Democratic Party election fundraising eventsparticularly events seeking campaign funds from the banking and financial sector. Meanwhile, polls showed that increasing segments of the public were following the protests in the news and had become concerned about inequality. Although many did not approve of the protesters themselves, they did embrace their central issue. Leading Democratic Party politicians avoided the topic of inequality for more than two months after the protests began, but under pressure of strategic occupations, growing press coverage, and shifting opinion polls, they 
started to address it. By early December 2011, President Barack Obama delivered a major speech with a fairness and inequality theme.

Semantic analysis of U.S. media online sites (using Silobreaker) from before the first Occupy protests in September 2011 through February 2012 shows the development of inequality discourse in the national media and blogs over this time. In the early period (midSeptember to mid-October 2011), journalists, bloggers, and political analysts pegged the inequality story to the protests themselves. Even as late as November 2011, tracking the cooccurrences of the terms "inequality" and "occupy" showed that the terms most closely associated with Occupy and inequality were "Adbusters,"6 "taxes," and, at some remove, a cluster of conservative oppositional terms that included the Republican Party and the Tea Party, which shared some concerns about the misdeeds of the banks but disagreed with the economic justice remedies favored by many Occupy protesters. By contrast, terms such as "Democratic Party," "unions," "White House," "Obama administration," and "Obama" barely registered in the early months of increasingly dense media discourses (thousands of news and blog posts per month) surrounding the key terms of "inequality" and "occupy."

The discourse networks changed dramatically in early December of 2011 when Obama held a speech in Kansas that echoed President Theodore Roosevelt's address on economic fairness nearly a century before. Suddenly, Obama moved into the center of the discourse network to join "Occupy Wall Street" as the primary media sources in news articles and blog discussions of "inequality." In the month of December 2011, Obama and Occupy were the actors most often associated with mentions of inequality in news, commentary, and blogs. Figure 6 shows the semantic network surrounding the inequality debate in the U.S. in December 2011. The discourse association network is based on 520 online news items, and 134 blogs. By the time of his January 2012 State of the Union Speech, U.S. news reports and political commentary disproportionately associated the term “inequality” with Obama. 
Figure 6. Semantic Network of US Inequality Media Debate, December 2011

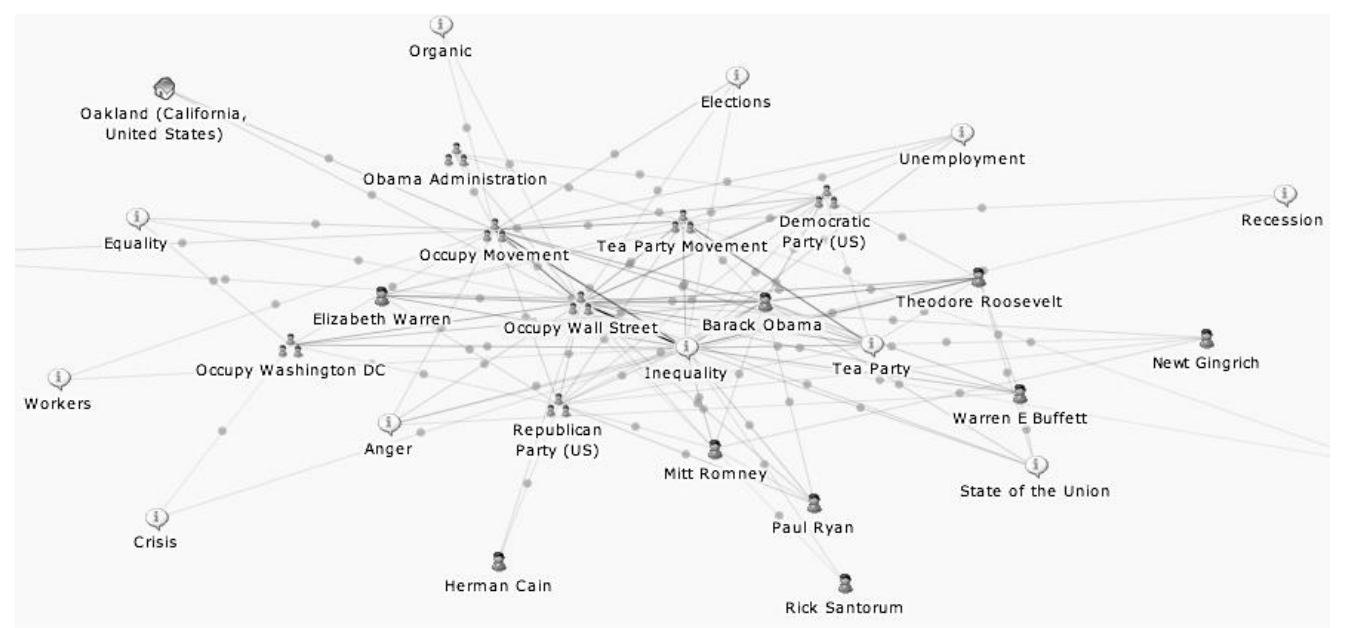

Note: Based on 520 news articles and 134 blogs, Source: Silobreaker, with permission.

When the Occupy camps were evicted in late 2011, Occupy-related initiatives continued, but focus shifted from occupations of public space to other kinds of initiatives, such as Occupy Our Homes and, eventually, the Occupy (hurricane) Sandy crisis relief effort and the Rolling Jubilee debt resistance campaign. A Silobreaker analysis from November 2013 shows that "Occupy Wall Street" had drifted to the edge of the public discourse about inequality, but that the national media discourse on the topic remained vibrant. The topic remained most closely associated with Obama, with the Republican Party appearing in opposition to various Democratic Party policy proposals. The debate at this time became associated with a number of interrelated policy issues such as "minimum wage," "workers," and "taxes," as well as more general issues such as "democracy" and "equality."

This shift from the early public discourse about issue framing to later policy discussions paralleled the cases of Internet freedom and the Robin Hood tax. Perhaps reflecting the breadth of the issue, media attention around inequality during the policy phase was even more dramatic. A November 2013 Silobreaker analysis showed 3864 online news items and 1645 blogs addressing the central topic of inequality, centering on how the problem of inequality had become intertwined with a host of core public policy issues in the U.S.

It may seem surprising that such a dispersed protest network could have a similar impact on public attention and the political agenda as the more structured and high-resource networks in our earlier cases. The Occupy case suggests that very different ways of distributing power in networks can shape public debate and point toward political policy outcomes. This said, the specific political responses from government following Occupy were clearly less defined by demands from the protest network than was the case with either 
SOPA-PIPA or the Robin Hood tax campaign. Such differences in the terms of particular political solutions may reflect differences in how power is organized in these networks.

\section{CONCLUSION}

Large-scale technology-enabled networks accord communication a prominent organizational role. This in turn raises the possibility that the organization of power in the form of public attention and recognition in technology-enabled contention necessarily reflects the power-law distribution overwhelmingly observed in other online networks. By contrast, we argue that distinct configurations may emerge in technology-enabled contention and that these differences may reflect actors' values and technology preferences. The article identified three broad ideal types of power signatures based on public attention and recognition in technologyenabled networks: concentrated, moderate and dispersed.

Whether viewed from the perspective of quality of participation or outcomes, none of the three models represents a superior alternative as such. Without further evidence, it is not clear which is better in terms of devolving power and political efficacy down to the level of individuals. While intuition may suggest that dispersed power facilitates equal participation or that concentrated power is restrictive, such assessment is complicated by the fact that some forms of action that are designed to be inclusive can become exclusionary (Polletta 2013), while some forms of structured dominance are intended to safeguard the action of average individuals (Kreiss, Finn, and Turner 2011). In terms of outcomes, the cases suggest that all three types are capable of producing similar outcomes, in terms of public discourse framing and government policy initiatives, even if the majority of actual cases are not as successful as the ones discussed here.

We propose that it is crucial to continue to pursue a more nuanced understanding of the organization of power in technology-enabled contention as part of the broader endeavor to research collective action through networks. The organization of power contributes importantly to shaping the action, and ultimately to the processes entailed in framing the actors and issues involved. Moving forward, this preliminary discussion, therefore, suggests a vivid research agenda that centers on three key areas.

First, and most specifically, it is important to understand how the mechanisms discussed here interact with the other dimensions and manifestations of an action network. This is not merely a matter of reconciling mediated displays of attention with other recognition structures. We need a better understanding of how specific micro-level processes scale up into particular network power signatures (González-Bailón et al. 2013; Margetts, et 
al. 2013), how action mechanisms in multi-dimensional networks converge (Pavan this issue) and collide (Bennett and Segerberg 2013), and how such dynamics affect the processes involved in shaping action and framing issues (della Porta and Mattoni 2014; Postill 2013). Importantly, such investigations require moving the analysis forward with multiple methods that illuminate action in the broader and more constricted network circles, both online and offline.

Second, and relatedly, these patterns of attention and recognition do not represent all the ways of thinking about power in networks. It is important to examine the role played by other dimensions of power and by their associated mechanisms in shaping the action. The latter include a variety of communication-centered mechanisms (see Kavada 2014) and the control of particular technologies, which may be examined in such elements as the capacity to operate digital switches in communication networks (Castells 2011), the struggles over access to social media accounts that can disrupt communication flowing from protests (Kavada 2014), and the material and ideological conditions underpinning the platforms that dominate the communicational context (Van Dijck and Poell 2013).

Finally, power in technology-enabled networks may have as much to do with the opportunity structures and political contexts in which those networks operate as with the conditions of communication. We suspect that digital media may make technology-enabled mobilizations both sensitive and adaptive to complex and changing political contexts, and our illustrative cases suggest that the complex array of digital and social media available to activists in the current era enables many flexible organizational forms. Developing a nuanced conceptual vocabulary for describing the organization of power in technology-enabled networks can allow us to examine this variety, and makes it possible to trace the same network as it shifts among different distributions over time, as happened in the SOPA/PIPA case. In this view, the organization of power and the way in which it is projected depend on both the organizational ideals (and conflicts) of activists and the contexts in which they operate. The implications of political context for technology-enabled contention is another important area for future work.

The rich avenues for exploring power in networks suggest that the quest is not for an overarching theorem or law about the proper organization of power in technology-enabled contention. Nor do we see a binding generalization about which pattern works best. Rather, a key analytical trajectory entails recognizing different ways of organizing power to achieve particular results. As part of such analysis, it is important to acknowledge that important elements of the organization of power in technology-enabled contention relate to how 
activists themselves think about it, how various technology choices shape it, and how these factors interact to produce more or less effective results in particular political contexts.

\section{NOTES}

1. For other arguments regarding contextualization problems in the power-law debate, see O’Neil (2014); Miconi (2014).

2. There are more refined tests for power laws, although there is also disagreement over how best to identify and compare them. Looking at the degree of fit in the tail of the distribution is one common method. Figure 1 simply sketches the general theoretical shape of a power law. 3. An interactive version of the Benkler et al. (2013) visualizations can be found here: http://cyber.law.harvard.edu/research/mediacloud/2013/mapping_sopa_pipa/\#.

4. The YouTube material can be found here: http://www.youtube.com/user/RobinHoodTax. 5. See Bennett, Segerberg, and Walker (2014) for dynamic modelling of crowd organization. 6 A consumer culture critique organization that issued the most visible early call for the occupations.

\section{REFERENCES}

Ackland, Robert, and Mathieu O’Neil. 2011. "Online Collective Identity: The Case of the Environmental Movement.” Social Networks 33(3): 177-190.

Amenta, Edwin, Neil Caren, Elizabeth Chiarello, and Yang Su. 2012. "The Political Consequences of Social Movements." Annual Review of Sociology 36: 287-307.

Anduiza, Eva, Camilo Cristancho, and José M. Sabucedo. 2014. "Mobilization through Online Social Networks: The Political Protest of the Indignados in Spain." Information, Communication \& Society 17(6): 750-64.

Barabási, Albert-László. 2003. Linked: How Everything Is Connected to Everything Else and What It Means for Business, Science, and Everyday Life. New York: Penguin.

Barabási, Albert-László, and Réka Albert. 1999. "Emergence of Scaling in Random Networks.” Science 286(5439): 509-12.

Baym, Geoffrey, and Chirag Shah. 2011. "Circulating Struggle: The Online Flow of Environmental Advocacy Clips from The Daily Show and The Colbert Report." Information, Communication \& Society 14(7): 1017-1038.

Benkler, Yochai, Hal Roberts, Robert Faris, Alicia Solow-Niederman, and Bruce Etling. 2013. "Social Mobilization and the Networked Public Sphere: Mapping the SOPAPIPA Debate.” Cambridge, MA: Berkman Center Research Publication. Retrieved November 5, 2013. (http://ssrn.com/abstract=2295953). 
Bennett, W. Lance, and Alexandra Segerberg. 2012. "The Logic of Connective Action: Digital Media and the Personalization of Contentious Politics." Information Communication \& Society 15(5): 739-68.

- 2013. The Logic of Connective Action: Digital Media and the Personalization of Contentious Politics. Cambridge, UK: Cambridge University Press.

Bennett, W. Lance, Alexandra Segerberg, and Shawn Walker. 2014. "Organization in the Crowd: Peer Production in Large-Scale Networked Protests." Information, Communication \& Society. 17(2): 232-60.

Brasset, James. 2012. "Global Justice and/as Global Democracy: The UK Campaign for a Tobin Tax." Pp. 254-72 in Global Justice Activism and Policy Reform in Europe: Understanding when Change Happens, edited by Peter Utting, Mario Pianta, and Annekathrin Ellersiek. New York: Routledge.

Castells, Manuel. 2011. “A Network Theory of Power." International Journal of Communication 5: 773-87.

Chadwick, Andrew. 2013. The Hybrid Media System: Politics and Power. New York: Oxford University Press.

Della Porta, Donatella. 2013. "Bridging Research on Democracy, Social Movements and Communication." Pp. 21-38 in Mediation and Protest Movements, edited by Bart Cammaerts, Alice Mattoni, and Patrick McCurdy. Chicago: Intellect.

Della Porta, Donatella, and Mario Diani. 2006. Social Movements: An Introduction. Malden, MA: Blackwell.

Della Porta, Donatella, and Alice Mattoni. 2014. "Adapting Theories on Diffusion and Transnational Contention through Social Movements of the Crisis: Some Concluding Remarks.” Pp. 277-92 in Spreading Protest: Social Movements in Times of Crisis, edited by Donatella della Porta and Alice Mattoni. Colchester, UK: ECPR Press.

Diani, Mario. Forthcoming. The Cement of Civil Society: Civic Networks in Localities. Cambridge, UK: Cambridge University Press.

Diani, Mario, and Doug McAdam, eds. 2003. Social Movements and Networks: Relational Approaches to Collective Action. Oxford, UK: Oxford University Press.

Earl, Jennifer, and Katrina Kimport. 2011. Digitally Enabled Social Change: Activism in the Internet Age. Cambridge, MA: MIT Press

Farrell, Henry, and Daniel Drezner. 2008. "The Power and Politics of Blogs.” Public Choice 134: $15-30$. 
Freeman, Jo. 1975. "The Tyranny of Structurelessness.” Pp 282-88 in Radical Feminism, edited by Anne Koedt, Ellen Levine, and Anita Rapone, New York: Quadrangle Books.

Gaby, Sarah, and Neal Caren. 2012. "Occupy Online: How Cute Old Men and Malcolm X Recruited 400,000 Users to OWS on Facebook." Social Movement Studies 11(3-4): 367-74.

Gerbaudo, Paolo. 2012. Tweets and the Streets: Social Media and Contemporary Activism. London: Pluto Press.

Giugni, Marco. 1998. "Was it Worth the Effort? The Outcomes and Consequences of Social Movements.” Annual Review of Sociology 24: 371-93

Greenberg, Andy. 2012. "How Reddit's Alexis Ohanian became Mayor of the Internet." Forbes, June 6,. Retrieved October 16, 2014 (http://onforb.es/L144rB).

González-Bailón, Sandra, Javier Borge-Holthoefer, and Yamir Moreno. 2013. "Broadcasters and Hidden Influentials in Online Protest Diffusion." American Behavioral Scientist 57(7): 943-65.

Hardy, Cynthia, and Stewart Clegg. 2006. "Some Dare Call it Power." Pp. 754-75 in The SAGE Handbook of Organization Studies, edited by Stewart Clegg, Cynthia Hardy, Thomas Lawrence, and Walter Nord. London: Sage Publications.

Hearn, Jonathan. 2012. Theorizing Power. Basingstoke, UK: Palgrave Macmillan.

Hindman, Matthew. 2008. The Myth of Digital Democracy. Princeton, NJ: Princeton University Press.

Karpf, David. 2012. The MoveOn Effect: The Unexpected Transformation of American Political Advocacy. New York: Oxford University Press.

Kavada, Anastasia. 2013. "Internet Cultures and Protest Movements: The Cultural Links between Strategy, Organizing and Online Communication.” Pp. 75-94 in Mediation and Protest Movements, edited by Bart Cammaerts, Alice Mattoni, and Patrick McCurdy. London, Intellect.

- 2014. "Social Media and Power Relations in Decentralized Protest Movements: The Case of Occupy London." Paper presented at the European Consortium for Political Research General Conference, September 4-6, Glasgow, UK.

Kreiss, Daniel, Megan Finn, and Fred Turner. 2011. "The Limits of Peer Production: Some Reminders from Max Weber for the Network Society." New Media \& Society 13(2): 243-59. 
Langford, Catherine. 2013. "Free Speech in Cyberspace: A Rhetorical Analysis of SOPA and PIPA Cyberprotests.” First Amendment Studies 47(2): 85-105.

Loudon, Melissa. 2014. “'Research in the Wild' in Online Communities: Reddit's Resistance to SOPA." First Monday 19(2). Retrieved July 7, 2014 ( DOI:10.5210/fm.v19i2.4365).

Lukes, Steven. 2005. Power: A Radical View. 2nd ed. Basingstoke, UK: Palgrave Macmillan.

Margetts, Helen, Peter John, Scott Hale, and Stephanie Reissfelder. 2013. "Leadership without Leaders? Starters and Followers in Online Collective Action." Political Studies. Retrieved October 16, 2014 (DOI: 10.1111/1467-9248.12075).

McAdam, Doug, Sidney Tarrow, and Charles Tilly. 2001. Dynamics of Contention. Cambridge, UK: Cambridge University Press.

Meraz, Sharon, and Zizi Papacharissi. 2013. "Networked Gatekeeping and Networked Framing on \#egypt.” International Journal of Press and Politics 18(2): 138-166.

Miconi, Andrea. 2014. “Italy's Five Star Movement and the Role of a Leader: Or How Charismatic Power Can Resurface on the Web." New Media \& Society. Retrieved April 15, 2014 (DOI: 10.1177/1461444814520872).

O'Neil, Mathieu. 2009. Cyberchiefs: Autonomy and Authority in Online Tribes. London: Pluto Press.

—. 2014. "Hacking Weber: Legitimacy, Critique, and Trust in Peer Production." Information, Communication \& Society 17(7): 872-88.

Polletta, Francesca. 2013. "Participatory Democracy in a New Millennium." Contemporary Sociology 42(1): 40-50.

Postill, John. 2013. "The Uneven Convergence of Digital Freedom Activism and Popular Protest: A Global Theory of the New Protest Movements." Melbourne, AU: RMIT University. Retrieved December 18, 2013 (http://rmit.academia.edu/JohnPostill).

Rogers, Richard. 2004. Information Politics on the Web. Cambridge, MA: The MIT Press. . 2013. Digital Methods. Cambridge, MA: The MIT Press.

Sell, Susan. 2013. 'Revenge of the 'Nerds': Collective Action Against Intellectual Property Maximalism in the Global Information Age.” International Studies Review 15: 67-85. Shaw, Aaron, and Benjamin Mako Hill. 2014. "Laboratories of Oligarchy? How the Iron Law Extends to Peer Production." Journal of Communication 64(2): 215-38.

Shirky, Clay. 2003. "Power Laws, Weblogs and Inequality: Clay Shirky's Writings about the Internet.” Retrieved December 2013 (http://www.shirky.com/writings/powerlaw_weblog.html). 
Tarrow, Sidney. 2011. Power in Movement: Social Movements and Contentious Politics. 3rd ed. New York: Cambridge University Press.

Twitter. 2012. Twitter message from account @ Twitter dated January 18, 2012, 16.37, Retrieved October 16, 2014 (https://twitter.com/twitter/status/159796576569655296).

Van Dijck, José, and Thomas Poell. 2013. “Understanding Social Media Logic.” Media and Communication 1(1): 2-24.

Weber, Max. 1978. Economy and Society. Berkley, CA: University of California Press.

Weisman, Jonathan. 2012. "After an Online Firestorm, Congress Shelves Antipiracy Bills." $\begin{array}{llll}\text { New } & \text { York } & \text { Times, } & \text { January }\end{array}$ (http://www.nytimes.com/2012/01/21/technology/senate-postpones-piracyvote. html).

Wilkinson, Dennis. 2009. "Strong Regularities in Online Peer Production.” Pp 302-09 in EC '08 Proceedings of the 9th ACM Conference on Electronic Commerce, New York, NY: ACM.

Yanacopulos, Helen. 2009. “Cutting the Diamond: Networking Economic Justice.” Pp. 67-78 in Networked Politics: Agency, Power and Governance, edited by Miles Kahler. Ithaca, NY: Cornell University Press. 